\section{Brain, Behavior and Evolution}

Beltz, B.S. 146

Benton, J.L. 146

Bonfanti, L. 205

Brenneis, G. 146

Dunlap, K.D. 156

LaDage, L.D. 184

Lipp, H.-P. 205
Øverli, Ø. 167

Powers, A.S. 143,175

Pytte, C.L. 191

Sørensen, C. 167

\title{
Subject Index Vol. 87, No. 3, 2016
}

Adult hippocampal neurogenesis 205

- mammalian neurogenesis 205

- neural stem cells 146

Amphibian 175

Area X 191

Behavior 191

Behavioral plasticity 156

Blood-brain barrier 146

Bone marrow 146

Brain evolution 205

- plasticity 156

- structural plasticity 205

Caudomedial nidopallium 191

Cell proliferation 156, 205

Doublecortin 205

Ecology 184

Environment 156

Evolution 184
Fish 156

Food storing 184

Frog 175

Hemocytes 146

Hippocampus 184

Home range 184

HVC 191

Immune system 146

Lizard 175

Migration 184

Motor 191

Navigation 184

Neurogenesis 156, 167, 175, 184, 191

Neuroplasticity 167

Plasticity 191
Reptile 175

Salamander 175

Season 175

Self-renewal 146

Snake 175

Songbird 191

Spatial cognition 184

Species differences 205

Stability 191

Stress 167

Subventricular zone 205

Territoriality 184

Testosterone 175

Turtle 175 